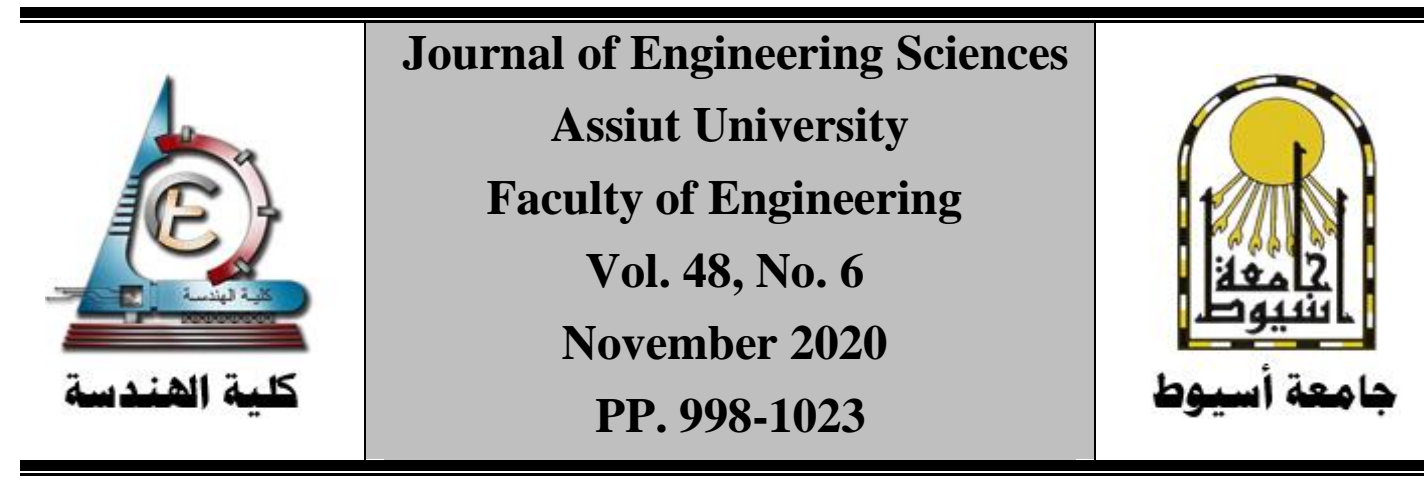

\title{
SOLUTIONS PROPOSED FOR THE NAVIGATION PROBLEM DOWNSTREAM ZEFTA BARRAGES
}

\author{
Wail A. Fahmy ${ }^{1}$ and Nasr Hekal ${ }^{2}$ \\ ${ }^{1}$ Lecturer, Civil Engineering Department, Shoubra Faculty of Engineering, Benha \\ University,E-mail: wailfamy@yahoo.com \\ ${ }^{2}$ Ass., Professor at Nile Research Institute, National Water Research Center, Email: \\ nasrhekal@gmail.com
}

Received: 26 August 2020; Revised: 5 September 2020; Accepted: 10 September 2020

\begin{abstract}
The Nile navigable Damietta branch extends between Cairo and Damietta open seaport on the Mediterranean. For safe navigation throughout the branch, a $2.30 \mathrm{~m}$ minimum flow depth (MFD) is required. A recovery project to improve the branch navigation was started in 1999 and completed in 2005. The project was to implement a $40 \mathrm{~m}$ wide navigable waterway. About 6.50 million $\mathrm{m} 3$ of bed materials had been removed from bottlenecks at $\$ 18.20$ million cost. In 2003, the construction of a new lock of $150.0 \mathrm{~m}$ length, $17.0 \mathrm{~m}$ width and (1.50) $\mathrm{m}$ bed level was completed on Zefta Barrages (ZB) east side to meet the navigation requirements. The barrages are located at Km 119.625 downstream (D/S) El-Roda g auge station. However, the resulting water stage (WS) D/S (ZB) during low discharges was insufficient to provide the MFD. Field studies were conducted to reveal the reasons. They found the branch flow carrying capacity had increased due to excessive dredging which caused a decline in WSs D/S (ZB). Analyzing the hydrologic and topographic conditions, two solution concepts were reached; either to raise the WS by $0.70 \mathrm{~m}$ or to lower the bed level of the diversion channel located $\mathrm{D} / \mathrm{S}$ the new lock by $1.0 \mathrm{~m}$. Therefore, this study aims to introduce solutions to overcome the problem. The solutions are to use a D/S rubber weir for raising the WS or construct a new lock within the $\mathrm{D} / \mathrm{S}$ diversion channel for lowering the bed level or build new barrages with a new lock.
\end{abstract}


KEYWORDS: River Nile; Damietta branch; Zefta barrages; Navigation problem; Navigation lock; Inflatable rubber weir.

\author{
Abbreviations: \\ $+\mathrm{MSL}=$ Above Mean Sea Level. \\ AHD = Aswan High Dam. \\ $\mathrm{Mm}^{3} / \mathrm{d}=$ Million cubic meters/day. \\ NRI = Nile Research Institute. \\ RG = Roda gauge station. \\ RTA = River Transport Agency. \\ $\mathrm{D} / \mathrm{S}=$ Downstream. \\ $\mathrm{U} / \mathrm{S}=\mathrm{Upstream}$; and \\ WS $=$ Water Stage.
}

\title{
1. Introduction
}

Damietta branch is the eastern branch bifurcated from the main River Nile stream at $\mathrm{Km} 26.50 \mathrm{D} / \mathrm{S}$ Roda gauge station (RG). This branch is used for irrigation purposes and is also a first-class two-way waterway for cargo transportation between Cairo and the Damietta open seaport on the Mediterranean Sea as shown in Figure (1). Zefta barrages were constructed on Damietta branch in 1903 and renovated in 1954. The barrages consist of 50 openings for water passage control, each of $5.0 \mathrm{~m}$ width and $4.0 \mathrm{~m}$ maximum head and rests at a bed level of (3.50) $\mathrm{m}$ above mean sea level (+MSL). There is an old $12 \times 64 \mathrm{~m}$ navigation lock of bed level equal to (3.50) $\mathrm{m}+\mathrm{MSL}$ at the west side. There are two irrigation and navigable canals branched off upstream (U/S) the barrages at the river west side. To ensure sufficient discharge releases through these canals, a broad-crested weir is constructed across the branch at $200 \mathrm{~m} \mathrm{D} / \mathrm{S}$ the barrages. To ensure safe and efficient cargo transportation through the branch, the following supporting actions have been taken into consideration by the River Transport Authority (RTA) over the last two decades as mentioned in an NRI Report (2005). It is worth mentioning that NRI is the navigation consultant (advisor) of RTA.

- A flow depth of $2.30 \mathrm{~m}$ was assigned as a minimum depth required for safe navigation. This depth is the sum of the maximum allowable ship draft $1.80 \mathrm{~m}$ and a $0.50 \mathrm{~m}$ keel clearance under the ship.

- The navigation lock chamber at Delta barrages on Damietta branch was renovated and lengthened to $100 \mathrm{~m}$ to accommodate for twin-ship barge 
units of $100 \mathrm{~m}$ total length and $11.60 \mathrm{~m}$ width. Also, a new port was constructed just $\mathrm{D} / \mathrm{S}$ the barrages.

- A total cost of about $\$ 18.20$ million was allocated to remove about 6.50 million cubic meters of bed materials at several bottlenecks along the branch between years 1999 and 2005 to maintain safe navigability and vessel maneuverability around the clock and to facilitate cargo transportation through the branch; and

- As the existing (old) lock chamber on the west side of Zefta barrages was no longer able to provide safe navigation services for the new ship fleet, a new lock of $150 \mathrm{~m}$ total length, $17 \mathrm{~m}$ width and (1.50) $\mathrm{m}$ bed level was constructed on the east side of the barrages in year 2003 as shown in Figures (2 and 3) at the cost of $\$ 32.50$ million.

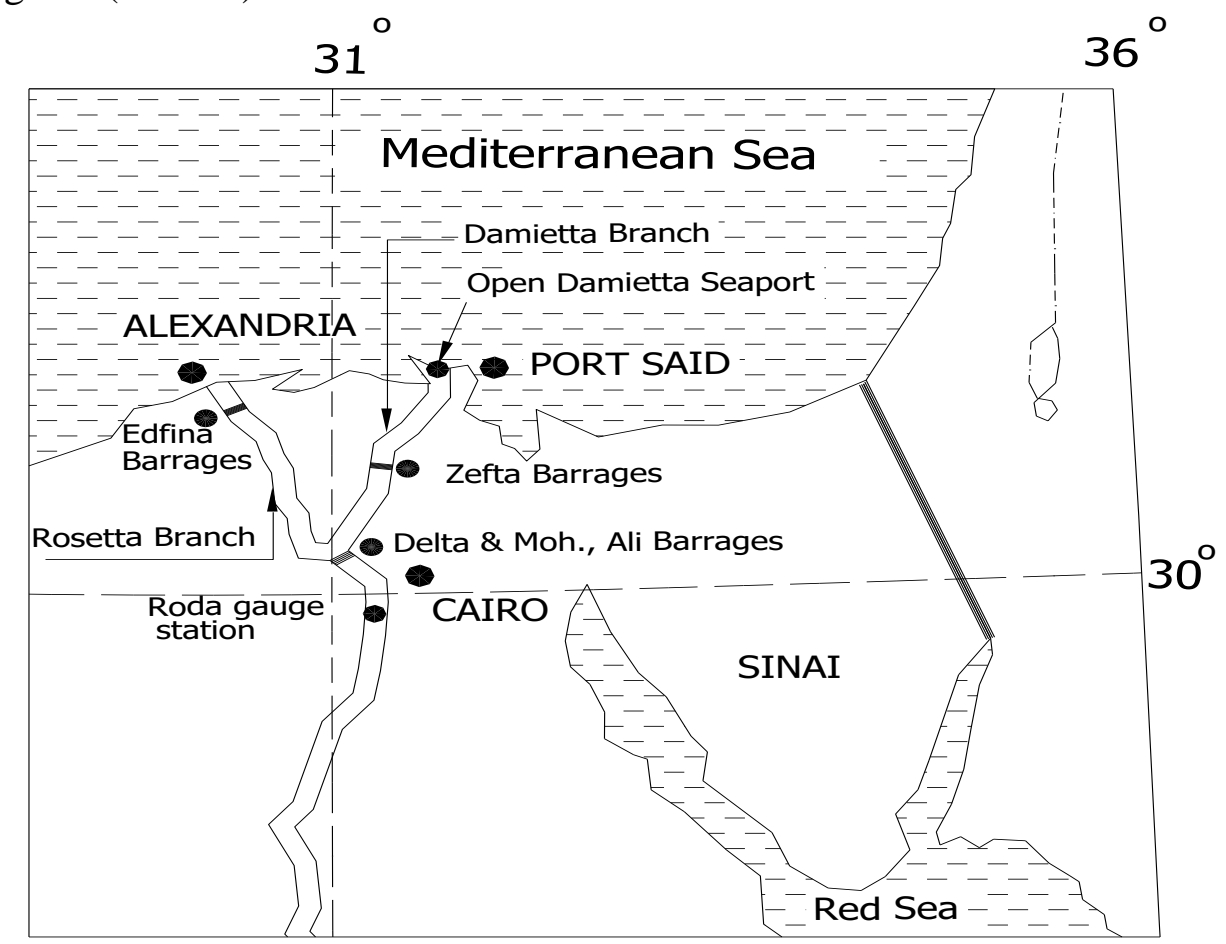

Fig. 1: Location of Zefta barrages on Damietta branch [1]

Several studies have been conducted to identify the morphological characteristics of Damietta branch as it is the most D/S and lowest reach of the River Nile alluvial plain. Examples of such studies are the ones conducted by Sadek et al. [3], Sadek and Hekal [4], and Negm [5]. After forty years of Aswan High Dam (AHD) operation, intensive studies were made by [1] on the River Nile bed morphology within Egypt. They revealed that Damietta branch had experienced excessive morphological changes 
which resulted in reducing its maximum flow capacity. The maximum recorded flow rate through the branch became 62.1 million $\mathrm{m}^{3} /$ day $\left(\mathrm{Mm}^{3} / \mathrm{d}\right)$ in 2002 instead of the $226 \mathrm{Mm}^{3} / \mathrm{d}$ that was recorded in 1961 prior to AHD construction.

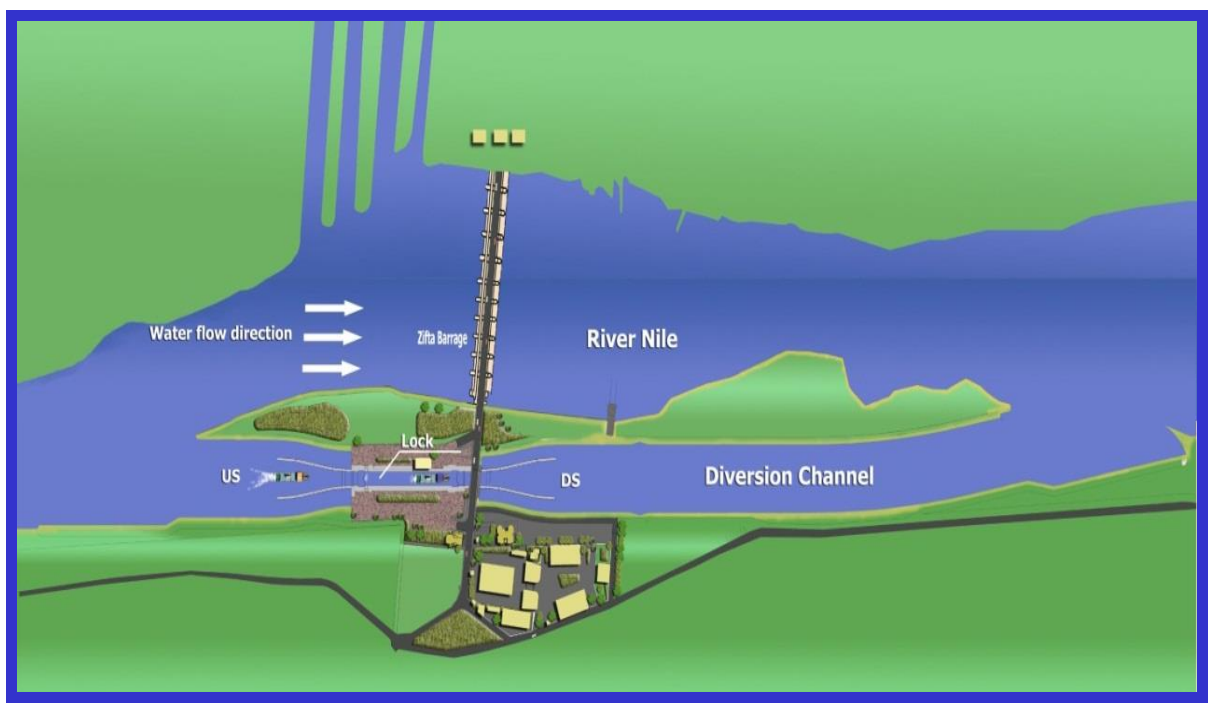

Fig. 2: A detailed arrangement of the new navigation lock.

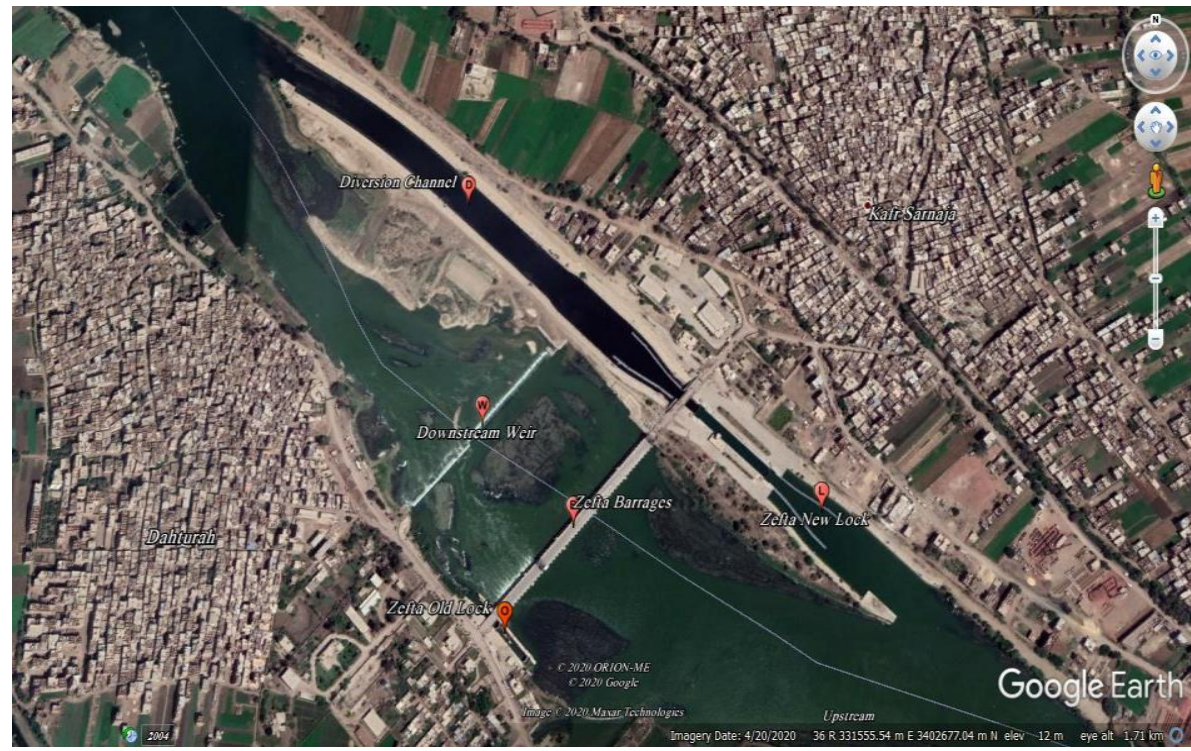

Fig. 3: General layout of Zefta barrages [2]

A detailed study for the existing condition D/S Zefta barrages was carried out by NRI [6] to evaluate the navigation situation at the end of the 
dredging activities. The study revealed that the water depth $\mathrm{D} / \mathrm{S}$ Zefta barrages during the low discharge period would not provide the depth required for safe navigation. The study attributed - as displayed in Figure (4) - the decline in the recorded water stage D/S the weir, especially during winter, to the excessive dredging works that had been accomplished. The study also showed that the recorded water stage D/S Zefta barrages weir was about (4.50) $\mathrm{m}$ when releasing $10.0 \mathrm{Mm}^{3} / \mathrm{d}$ during the period (19981999) before dredging. Then, the water stage, at the same discharge release, started to decline to (4.00) $\mathrm{m}$, then to (3.30) $\mathrm{m}$ during the periods (20032004) and (2006-2007) respectively as shown in Figure (4). This was attributed to the lowering of the riverbed that occurred due to the dredging works that had begun in 1999 and completed in 2005. Now, the navigation has been stopped through the reach especially during the minimum WS period lest ships might get aground.

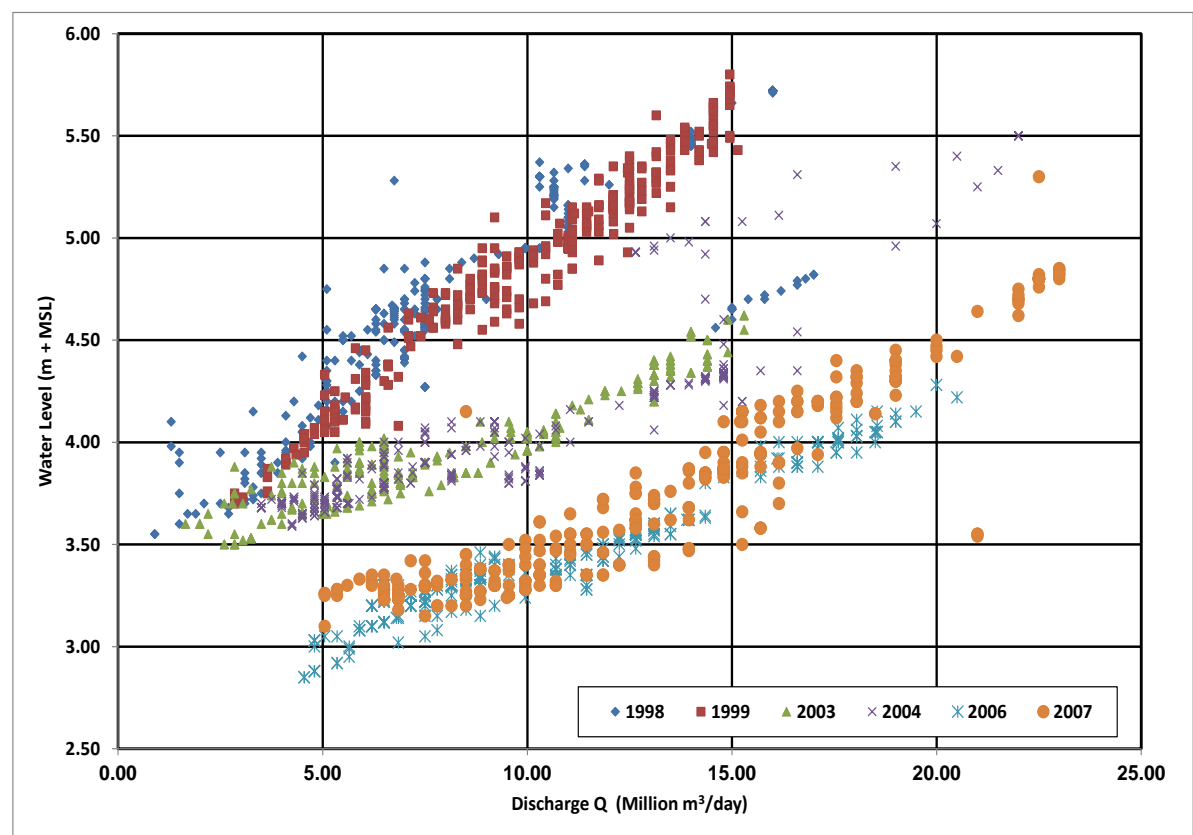

Fig. 4: Water stage drop due to dredging D/S Zefta weir.

A field survey study by NRI [7] staff and produced hydro-topographic maps for Damietta branch at Zefta barrages revealed that a staff gauge was positioned just D/S the weir and U/S two spur dikes as shown in Figure (5) at the west bank. The daily recorded readings of the gauge were found to be misleading because of the heading up and high turbulence occurring U/S the spur dikes. This had resulted in raising the recorded water surface levels more than the actual values. Field measurements also revealed that the 
actual WS at the outlet diversion channel of the new lock is about $0.5 \mathrm{~m}$ lower than that recorded at the D/S weir gauge as illustrated in Figure (6). This drop in WSs affected the navigation movement D/S Zefta Barrages and the weir. Accordingly, the study recommended that both short- and long-term solutions should be adopted as follows:

\section{Short term}

- $\quad$ To use partially loaded ship units with smaller draft depth especially during low discharges; and

- $\quad$ To reduce the under-keel clearance to less than $0.5 \mathrm{~m}$ according to the navigation density and the waterway condition.

\section{Long term}

- To extend the outlet diversion channel of the new navigation lock with lower bed level; or

- To construct new barrages provided with navigation lock D/S Zefta barrages.

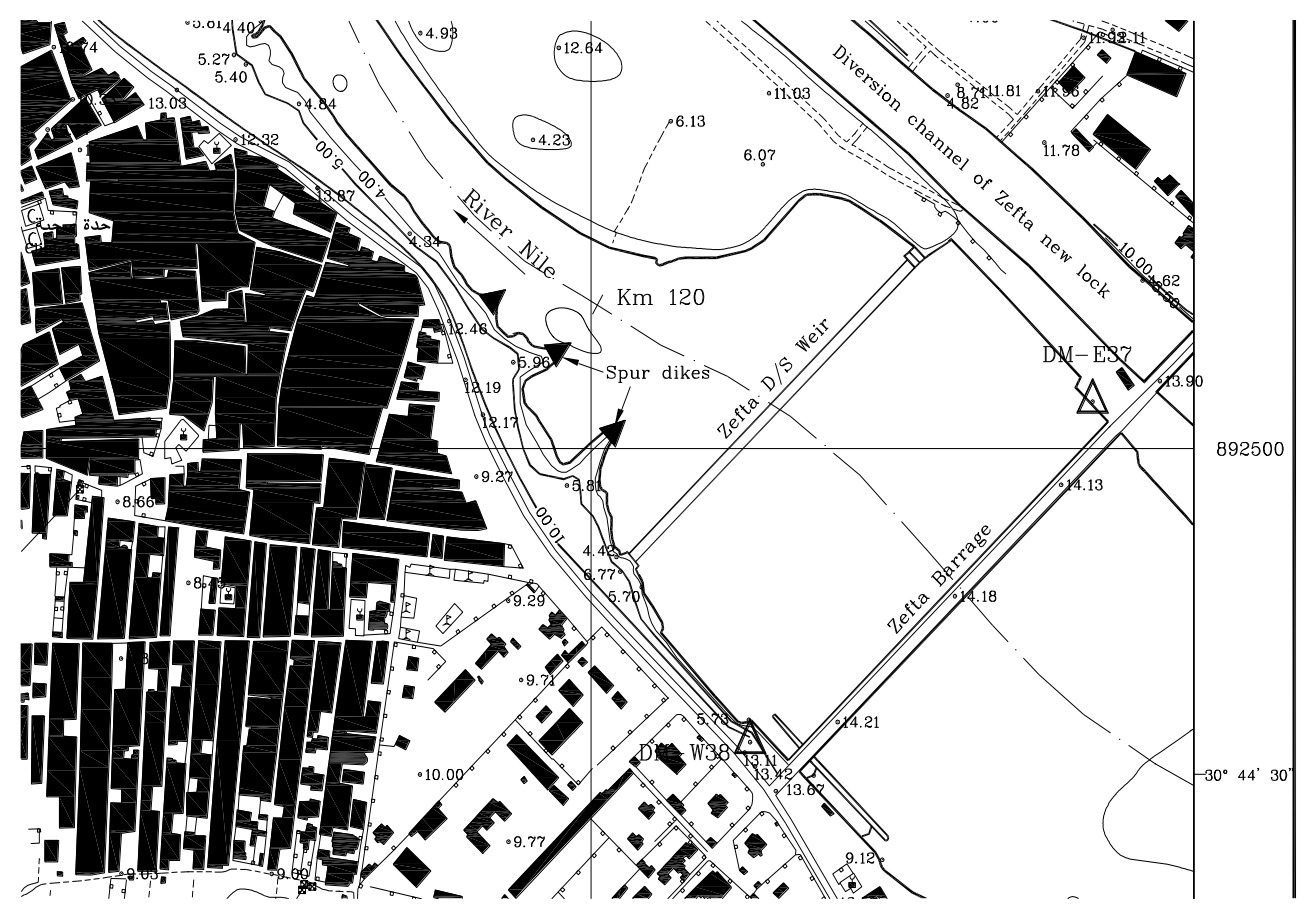

Fig. 5: Location of the D/S weir and staff gauge [1] 


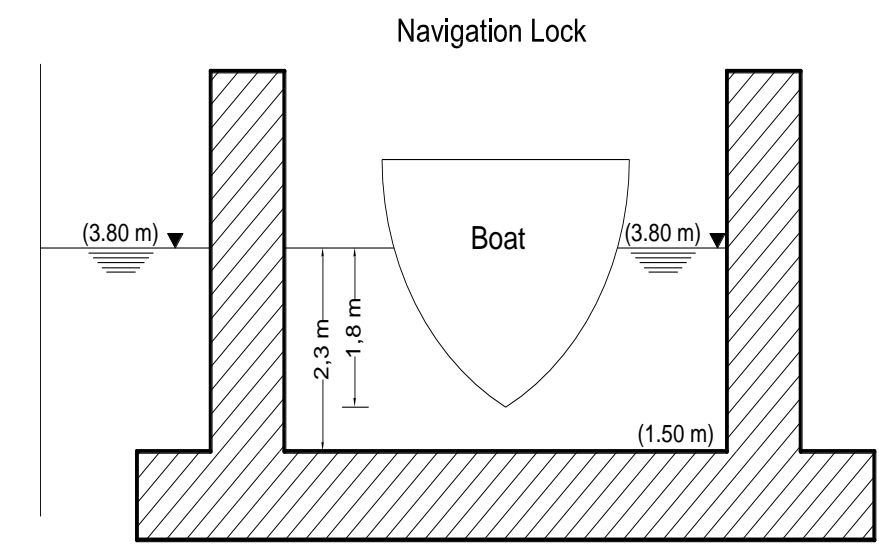

Fig. 6-a: The new navigation lock at the east side of Zefta barrages.

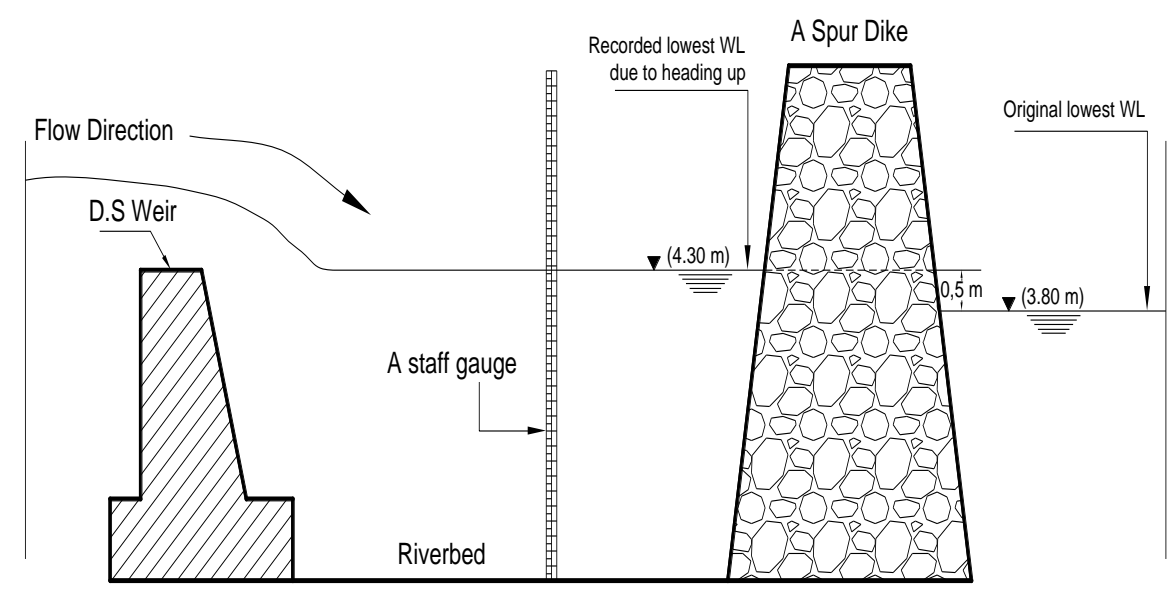

Fig. 6 - b: A sectional view looking from the river to the west bank showing positions of the D/S weir, staff gauge, and spur dike.

\section{Previous Work}

Previous research studies were carried out to cope with the problem. Applying numerical modeling, Raslan et al. [8] studied the consequences of dredging in Damietta branch from the point of view of the river regime and flow WSs. The study showed that sediment depositions would likely occur at several sites along Damietta branch where extensive dredging was carried out. Also, Ezzat [9] studied the application of successive weirs to raise WSs along Damietta branch D/S Zefta barrages to improve navigation conditions. Simulation of $134 \mathrm{~km}$ length of Damietta branch D/S Zefta barrages - using a 1-D numerical model - was carried out. Finally, the study revealed that there would be a $22 \%$ to $88 \%$ reduction in the number of navigation bottlenecks in 
case of constructing a series of weirs. Attia et al. [10] carried out similar efforts to raise WSs D/S Zefta barrages. The study recommended both weir construction and dredging to fulfill the best results from the economical point of view. To solve this problem, Kamel [11] introduced an application of spur dikes as permanent structures to overcome the resulted bottlenecks D/S Zefta barrages. The study showed that, to fulfill safe navigation all the year around, the minimum flow rate D/S Zefta barrages should not be less than 9.0 $\mathrm{Mm} 3 / \mathrm{d}$. At releasing a flow rate less than $5.0 \mathrm{Mm} 3 / \mathrm{d}$, the navigation safety can be secured by reducing the ship draft to $1.60 \mathrm{~m}$ and the under-keel clearance to $0.30 \mathrm{~m}$. Moreover, using NRI hydrographic maps of 2009, all bend parameters along Damietta branch were analyzed by Sadek et al. [12]. In that study, a total number of 53 bends were examined along Damietta branch and two bank protection types of spur dikes and graded limestone particles were proposed at some selected zones to enhance the efficiency of the navigation path along the branch.

\section{Problem Statement}

Despite carrying out the above studies, Damietta branch is still suffering a serious problem at the new lock of Zefta barrages and D/S the weir. There is no sufficient depth for safe navigation, especially during the low water discharge release period. The branch is no longer navigable. Therefore, the present study aims to discuss the causes of the problem and propose a number of practical solutions that can provide a sufficient flow depth for ensuring safe and efficient navigation D/S Zefta barrages and the weir all the year.

\section{Methodology}

\subsection{Data Collection}

To study this problem, there are two types of data that have to be collected and analyzed: field data and hydrological data.

\subsubsection{Field Data}

This kind of data includes carrying out topographic and bathymetric surveys for the study area. The topographic survey is meant to obtain information about the morphology (reliefs) of the riverbanks, while the bathymetric one is responsible for getting information on the riverbed morphology. Usually, the 
data are obtained in the form of points of coordinates $(\mathrm{X}, \mathrm{Y}, \mathrm{Z})$ where "Z" is the elevation above mean sea level.

\subsubsection{How data are gathered in the field:}

An NRI survey team (composed of civil engineers, surveyors, workers, and motorboat drivers) pack their riggings and set off for the study site to carry out hydrographic (topographic and bathymetric) surveys and investigations. They usually measure the river water stage levels using surveying instruments, such as TOTAL STATIONS and GPS units of international brands such as LEICA, SOKKIA, and TRIMBLE.

In order to measure the water stage level along the shoreline of the river segment under study, a competent surveyor sets up the Total Station unit at some position on either of the banks out of the river channel and starts to aim at different reflectors (targets) carried by a moving group of experienced workers along the shore line to observe some points as shown in Figure (7). If there is a staff gauge near the site, he takes its reading by the instrument and the water surface level is computed directly related to the mean sea level. It should be noted that the staff gauges are graded in centimeters and they give readings compared to the mean sea level. If there is no staff gauge near the study site, the surveyor takes a reading of the shoreline water surface and adjusts the instrument and continues his survey work until the end of the day. When the surveyor is back to office, he obtains the site water level by interpolating already two recorded readings (on the same day) of two staff gauges upstream and downstream the study site. For interpolation requirements, positions (kilometers) of the site and upstream and downstream staff gauges must be known.

Also, to measure the riverbed depths, a bathymetric survey has to be done. A motorboat equipped with a GPS system, echo sounder, laptop and skipper's screen are used for this task. Echo-sounding signals are sent to the riverbed through a transducer fixed at the keel (bottom) of the boat and received back instantly. Then, the signals are sent to the echo-sounding device that returns the water depth at once. Simultaneously, the DGPS (Differential GPS) picks signals by an antenna fixed on top of the boat (over the axis of the transducer) from satellites positioned in the outer space. The signals spot the position of the antenna with reference to a specific international datum such as the Universal Transverse Mercator (UTM). The antenna position is interpreted by the GPS into Coordinates (X and Y). A computer software package (HYPACK) is used to put this information together and returns the coordinates of the riverbed points in the form of $(\mathrm{X}, \mathrm{Y}, \mathrm{Z})$. Coordinate " $\mathrm{Z}$ " is computed by obtaining the water surface level that is usually obtained by a Total Station and a reference staff gauge and the water depth obtained by the echo sounder. 


\subsubsection{Interpretation of the Staff Gauge Reading Error D/S Weir}

In order to explain how the field survey team discovered that there was an error in the water stage level of $0.5 \mathrm{~m}$ at the staff gauge that is lying between the spur dike and the weir at the west bank, they took readings of another nearby staff gauge installed on the downstream side of Zefta Barrages as shown Figure (7). They also took a reading of the water surface at the east side of the river that is exactly opposite to the position of the first staff gauge. They found that the water surface of the shoreline at the east bank was 0.50 $\mathrm{m}$ lower than that at the west bank where the misleading staff gauge was. The measurements were repeated more than once for assurance, but the results still indicated the same error. Eventually, they could attribute that to the heading up occurring at the west bank due to the spur dike obstruction. Further, they could realize that the whole field measurements of the project of the new lock had relied on the staff gauge positioned upstream the spur dike.

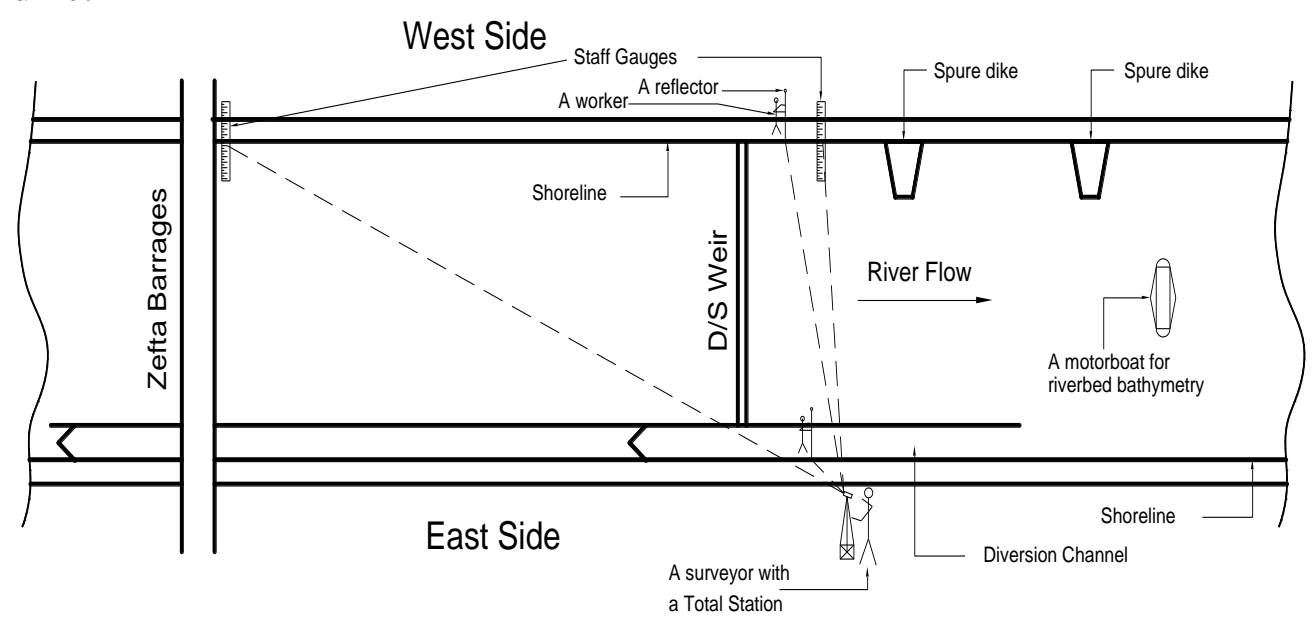

Fig. 7: A schematic diagram for field measurements

\subsubsection{Hydrological Data Collection}

By the hydrological data, we mean the historical recorded data of discharges and water levels of the study area. Usually, there are historical records over several past years that contain the daily discharges released downstream the Zefta Barrages. Also, the water stage levels corresponding to such discharges are recorded at downstream staff gauges positioned at riverbanks at specific kilometer that is referenced to the oldest staff gauge existing at Roda gauge station. This staff gauge is the start point of kilometrage $(\mathrm{km}=0.00)$. The historical discharges and water levels are arranged and stored in tables on the computer using excel spreadsheets or any other database software such that they can be recalled and processed quickly and in an easy manner. 


\subsection{Hydrological Data Analysis}

After completing the dredging works throughout Damietta branch and constructing the new navigation lock at Zefta Barrages, the bed level U/S the lock became (3.50) $\mathrm{m}+\mathrm{MSL}$ and (1.50) $\mathrm{m}+\mathrm{MSL}$ inside the lock chamber and through the $\mathrm{D} / \mathrm{S}$ diversion channel for a distance of about 1000 $\mathrm{m}$ long respectively. As the minimum flow depth required for safe navigation is $2.30 \mathrm{~m}$, the allowable lowest WS for passing a ship safely from $\mathrm{D} / \mathrm{S}$ through the diversion channel should be (3.80) $\mathrm{m}$. But the detailed field survey study mentioned earlier showed that there is a $0.50 \mathrm{~m}$ difference between the actual measured WS at the outlet diversion channel and that recorded $\mathrm{D} / \mathrm{S}$ the weir. The recorded WS is higher than the actual because of the heading up and turbulence generated U/S the existing spur dike as shown in Figure (5). This turbulence obstructs the flow just D/S the weir and raises the WS at the staff gauge. Accordingly, the readings taken include the error. Therefore, to provide a WS of (3.80) $\mathrm{m} \mathrm{D/S}$ the new lock at the outlet diversion channel, the monitored gauge reading $\mathrm{D} / \mathrm{S}$ the weir shouldn't be less than (4.30) $\mathrm{m}$ as illustrated in Figure $(6-\mathrm{b})$. To illustrate the navigation problem D/S Zefta barrages, the actual records for the yearly minimum flow discharges released D/S and the corresponding WSs U/S (US) and D/S the weir during the last ten years are listed in Table (1).

Table 1: Corresponding water surface levels to min. yearly discharges [1]

\begin{tabular}{|c|c|c|c|c|c|c|c|c|}
\hline \multirow[t]{2}{*}{ No. } & \multirow[t]{2}{*}{ year } & \multirow[t]{2}{*}{ Date } & \multicolumn{2}{|c|}{ Min. yearly discharge } & \multicolumn{4}{|c|}{ Corresponding water stage $(\mathrm{m})$ at } \\
\hline & & & $\begin{array}{c}\left(10^{6}\right. \\
\left.\mathrm{m}^{3} / \text { day }\right)\end{array}$ & $\left(\mathrm{m}^{3} / \mathrm{s}\right)$ & $\begin{array}{c}\text { US the } \\
\text { Barrages }\end{array}$ & $\begin{array}{l}\text { D/S the } \\
\text { Barrages }\end{array}$ & $\begin{array}{l}\text { D/S the } \\
\text { Weir }\end{array}$ & $\begin{array}{l}\text { Outlet of } \\
\text { the lock }\end{array}$ \\
\hline 1 & 2009 & 11 Dec. & 4.500 & 52.083 & 9.20 & 5.60 & 3.60 & 3.10 \\
\hline 2 & 2010 & 21 Jan. & 4.800 & 55.555 & 8.97 & 5.64 & 3.70 & 3.20 \\
\hline 3 & 2011 & 31 Jan. & 5.050 & 64.815 & 9.10 & 5.62 & 3.75 & 3.25 \\
\hline 4 & 2012 & 23 Dec. & 4.800 & 55.555 & 8.78 & 5.61 & 3.62 & 3.12 \\
\hline 5 & 2013 & 23 Dec. & 4.500 & 52.083 & 8.83 & 5.60 & 3.68 & 3.18 \\
\hline 6 & 2014 & 15 Jan. & 5.050 & 58.449 & 9.15 & 5.63 & 3.97 & 3.47 \\
\hline 7 & 2015 & 9 Dec. & 4.800 & 55.555 & 8.02 & 5.61 & 3.62 & 3.12 \\
\hline 8 & 2016 & 21 Jan. & 4.500 & 52.083 & 9.10 & 5.60 & 3.65 & 3.15 \\
\hline 9 & 2017 & $2^{\text {nd }}$ Jan. & 4.500 & 52.083 & 9.10 & 5.73 & 3.80 & 3.30 \\
\hline 10 & 2018 & 18 Dec. & 4.000 & 46.296 & 7.88 & 5.58 & 3.68 & 3.18 \\
\hline
\end{tabular}

From the Table, it can be found that the corresponding WS at the outlet diversion channel is taken as $0.50 \mathrm{~m}$ less than that recorded $\mathrm{D} / \mathrm{S}$ the weir as explained before and as shown in Figure (6). The Table shows that the minimum flow discharge $\mathrm{D} / \mathrm{S}$ Zefta barrages is $4.0 \mathrm{Mm}^{3} / \mathrm{d}$ and was recorded on December 18, 2018. Also, the minimum WS D/S the weir is $(3.60) \mathrm{m}$ and was recorded on December 11, 2009. Accordingly, this means that the actual WS at the diversion channel would be (3.10) $\mathrm{m}$ as listed and the 
available flow depth in this case would be only $1.60 \mathrm{~m}$ which is less than required for safe navigation.

Table 2: Yearly number of non-navigable days [1]

\begin{tabular}{c|c|c|c|c|c|c|c}
\hline \hline No. & year & $\begin{array}{c}\text { Detention } \\
\text { days }\end{array}$ & $\begin{array}{c}\text { Percent } \\
(\%)\end{array}$ & No. & year & $\begin{array}{c}\text { Detention } \\
\text { days }\end{array}$ & $\begin{array}{c}\text { Percent } \\
(\%)\end{array}$ \\
\hline \hline 1 & 1998 & 74 & $20.3 \%$ & 12 & 2009 & 286 & $78.4 \%$ \\
\hline 2 & 1999 & 65 & $15.3 \%$ & 13 & 2010 & 310 & $84.9 \%$ \\
\hline 3 & 2000 & 87 & $23.8 \%$ & 14 & 2011 & 304 & $83.3 \%$ \\
\hline 4 & 2001 & 114 & $31.2 \%$ & 15 & 2012 & 294 & $80.3 \%$ \\
\hline 5 & 2002 & 209 & $57.3 \%$ & 16 & 2013 & 291 & $79.7 \%$ \\
\hline 6 & 2003 & 304 & $83.3 \%$ & 17 & 2014 & 251 & $68.8 \%$ \\
\hline 7 & 2004 & 285 & $77.9 \%$ & 18 & 2015 & 226 & $61.9 \%$ \\
\hline 8 & 2005 & 318 & $87.1 \%$ & 19 & 2016 & 258 & $70.5 \%$ \\
\hline 9 & 2006 & 308 & $84.4 \%$ & 20 & 2017 & 207 & $56.7 \%$ \\
\hline 10 & 2007 & 208 & $59.5 \%$ & 21 & 2018 & 305 & $83.6 \%$ \\
\hline 11 & 2008 & 217 & $57.0 \%$ & 22 & 2019 & 277 & $75.9 \%$ \\
\hline
\end{tabular}

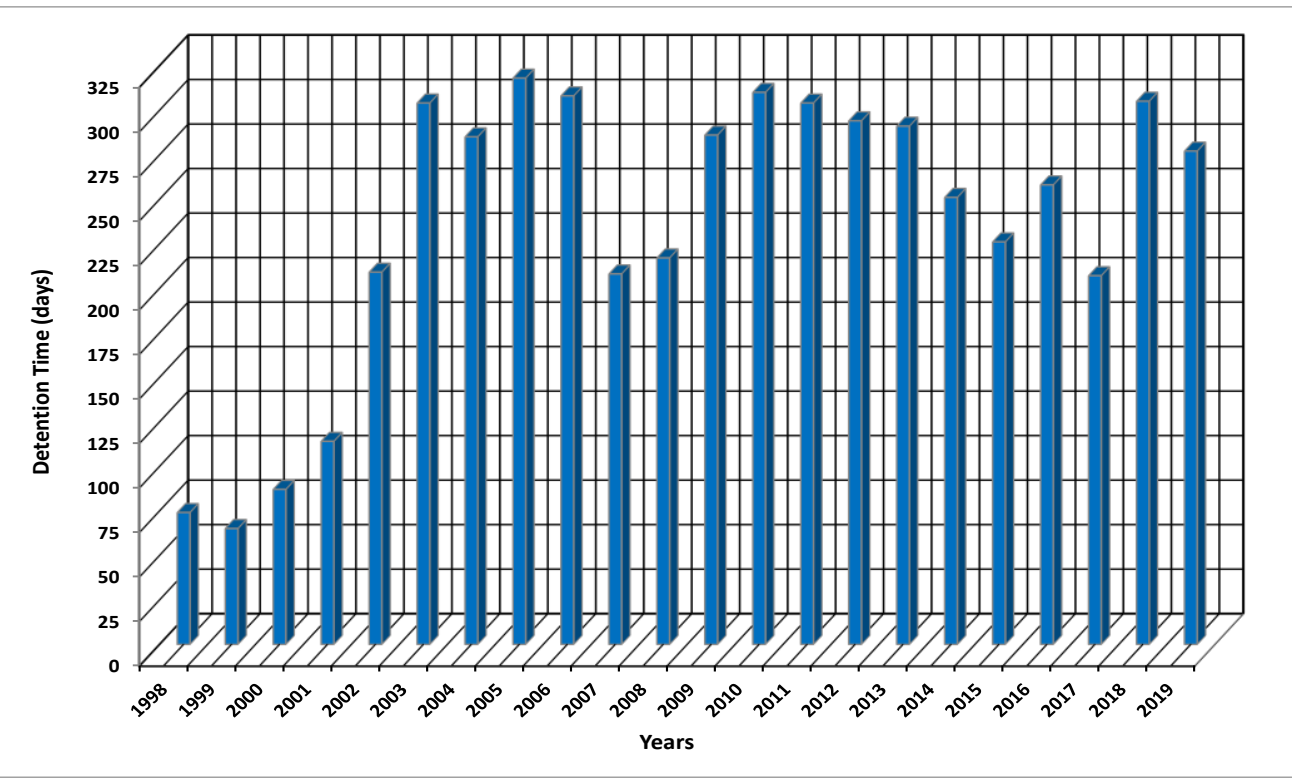

Fig. 8: Yearly records for non-navigable days.

The annual number of non-navigable days through the last 22 years has been collected and examined as shown in Table (2) and Figure (8). This number illustrates that the non-navigable period was only 65 days before the dredging activities started in 1999 and increased to 318 days in 2005 when the dredging work was completed. This explains that the observed drop in WS $\mathrm{D} / \mathrm{S}$ the weir was due to the excessive dredging works. Table (2) also shows 
that the annual average non-navigable period - D/S Zefta barrages over the period between 2002 and 2019 - is 260 days which is equivalent to $71.2 \%$ of the year. Additionally, Figure (9) illustrates the daily non-navigable days D/S Zefta barrages during 2018. They were found to be 305 days and equivalent to $83.60 \%$ of the year.

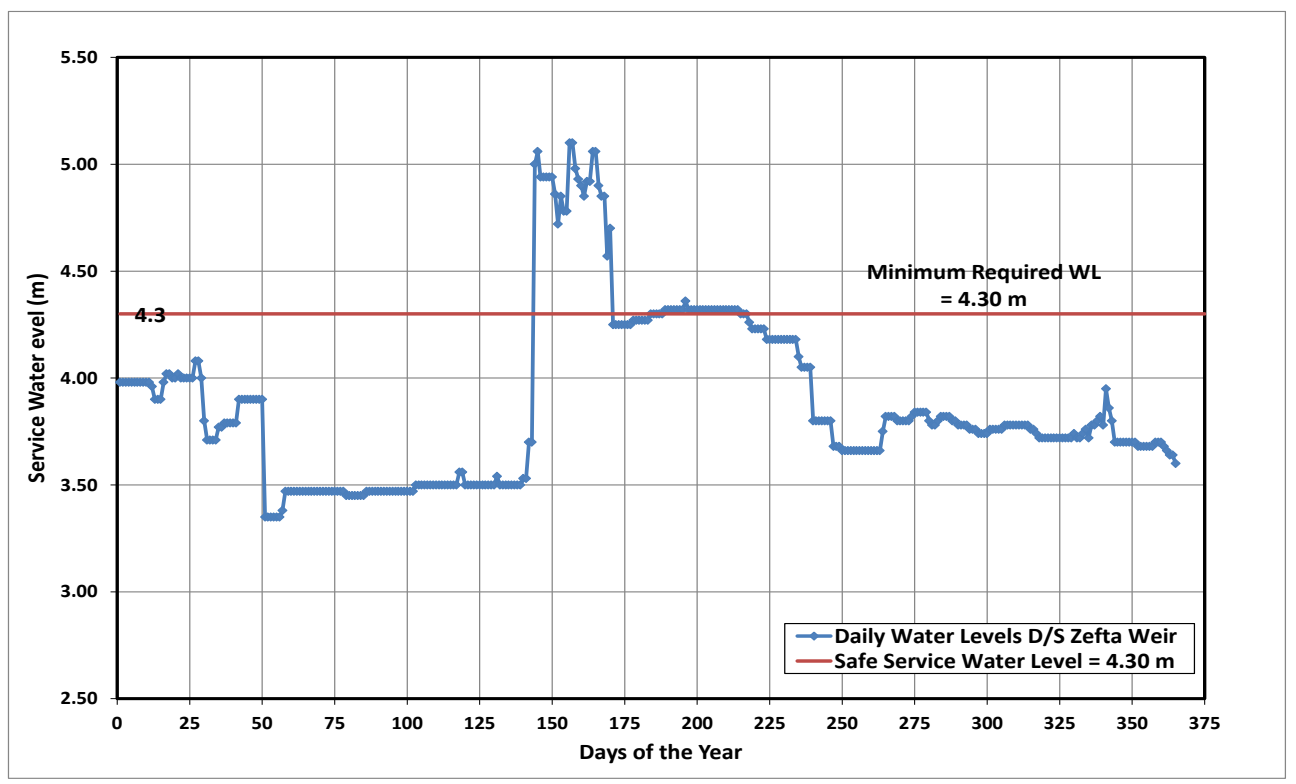

Fig. 9: Actual non-navigable days during year 2018

\subsection{Results of the Hydrological Analysis}

According to the abovementioned hydrological analysis, the flow depth D/S Zefta barrages was found inadequate for navigation especially in winter season when the flow rate released is least. Damietta branch has become nonnavigable for long periods of the year. This also means that the number of non-navigable days has increased again to reach a value very close to that happened in 2005. In other words, all the actions and attempts (the dredging work and construction of the new lock) taken to overcome the navigation problem throughout Damietta branch have failed.

To overcome this problem, either of the two following actions should be taken:

- The flow WS D/S the weir and subsequently at the outlet diversion channel is to be raised by $0.70 \mathrm{~m}$ : or

- The diversion channel bed is to be lowered by $1.00 \mathrm{~m}$. 


\section{Proposed Solutions}

To achieve the above recommended actions, four practical solutions are proposed as follows:

\subsection{Proposal (1): Using a Rubber Weir}

\subsubsection{Application of the Rubber Weir D/S Zefta Barrages}

Inflatable rubber weirs and dams have been used as water control structures for more than sixty years. They were first installed in Los Angeles of the United States of America in the mid-1950s. Beijing IWHR Corporation [13] and Zaoqiangdacheng Rubber Co., [14] mentioned that inflatable flexible membrane weirs and dams are flexible cylindrical inflatable structures made of rubberized material attached to a rigid base and inflated by air/water or combination of them as shown in Figure (10). A rubber weir can impound water flows to a specific level in a watercourse. Such a weir has numerous advantages over other types of water control gates. It has a simple operating system and can be installed on almost any channel cross-section shape with a relatively low cost. It can be applied for long spans up to $100 \mathrm{~m}$. Moreover, it can be installed as multiple spans of several hundred meters as illustrated in Figure (11). The longest one is of $1135 \mathrm{~m}$ with 16 spans, and the highest one is $6.0 \mathrm{~m}$. Also, a rubber dam of $2.25 \mathrm{~m}$ height and $50 \mathrm{~m}$ span was constructed in Kenya in 2010 (BIC rubber dam, Beijing IWHR Corporation). Also, an MSc study made by Abdel-Fadil [15] to reduce water evaporation losses from Nasser/Nubian Lake U/S AHD using closure dams proposed to use rubber dams. The study used different types of dams; earth-fill, rock-fill, and rubber in closing large khores (secondary channels). The study revealed that the rubber-type dam is the most relevant on. It also recommended to be used in open channels and canals for its low construction cost. Based on the previous successful usage of the rubber dam technique, it was found that it can be further used to solve the navigation problem $\mathrm{D} / \mathrm{S}$ barrages. 


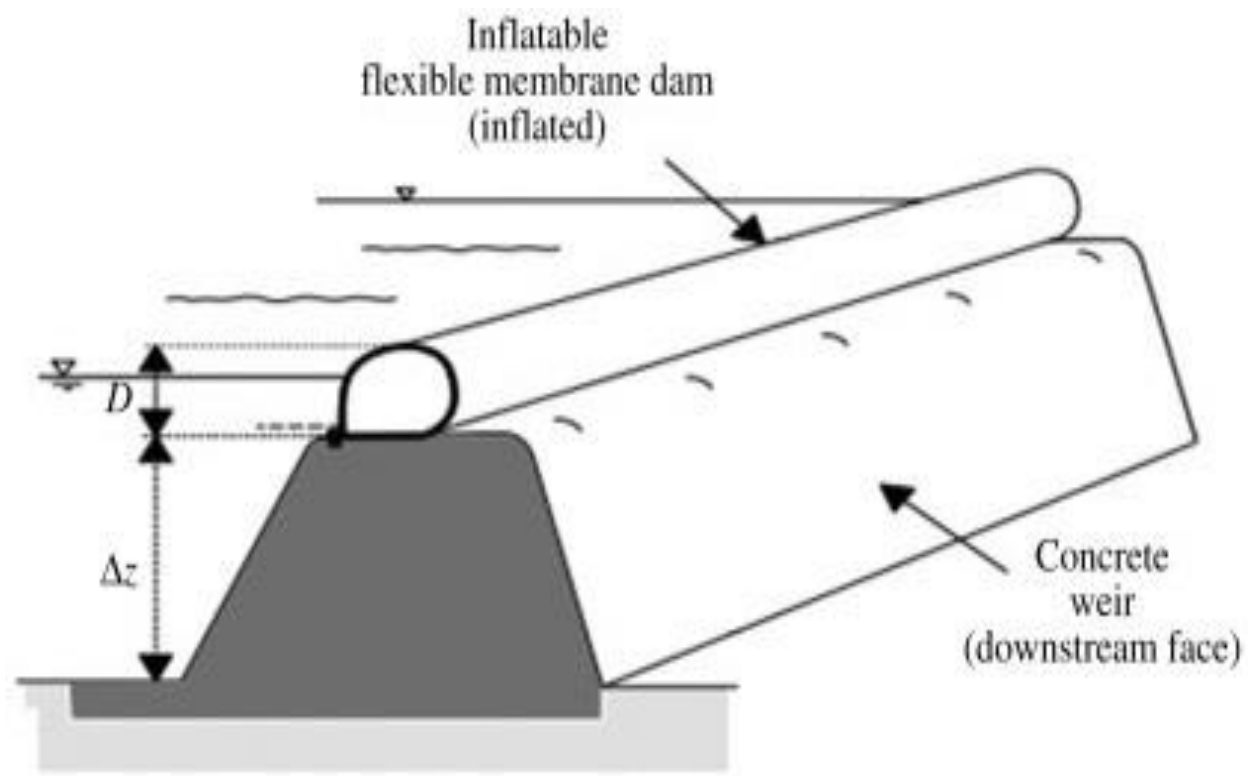

Fig. 10: Sketch of a rubber dam [16]

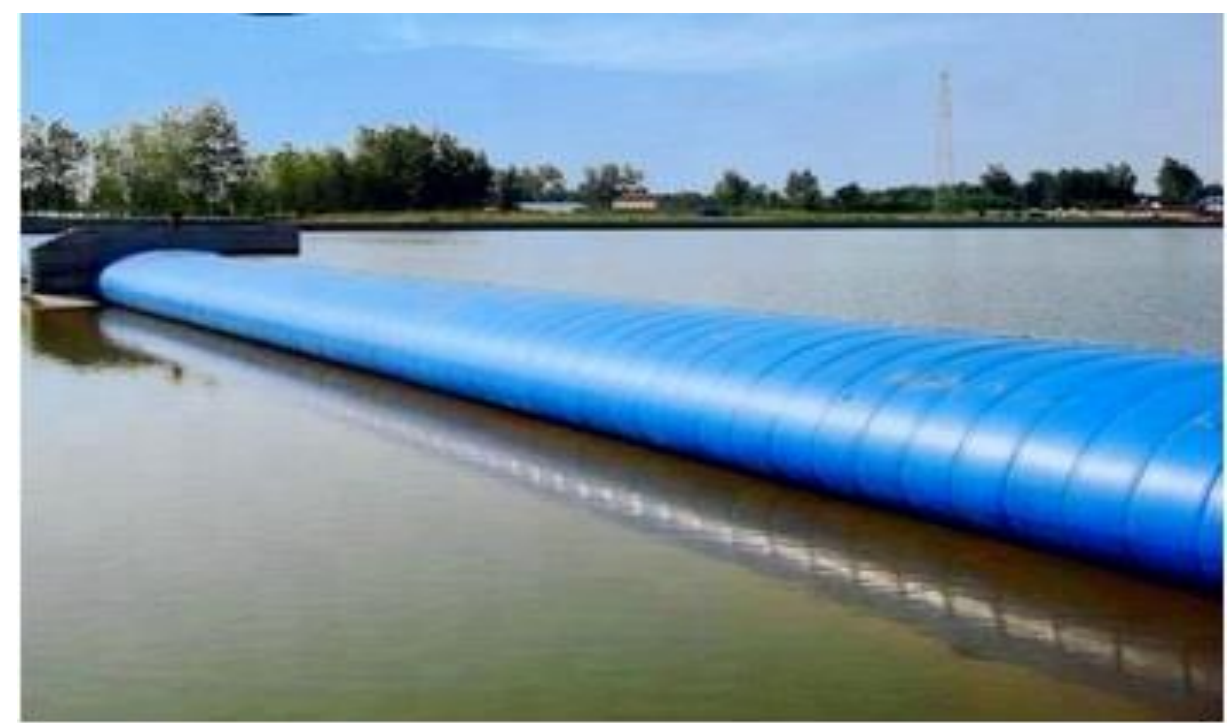

Fig. 11: Application of multiple spans rubber weir in open channel [17]

To raise the WS D/S the new navigation lock of Zefta barrages, a rubber weir is to be employed in the same way as shown in Figure (12). The rubber weir is to be installed across Damietta branch at a certain distance D/S Zefta barrages at a right angle with the flow direction. A cargo traffic route through the lock chamber of Zefta barrages should be run for unlimited successive cycles as illustrated in Figure (13). The starting time and duration of each traffic cycle should be assigned according to the results attained by a 
supplementary study previously prepared about traffic density, maximum cargo peak hours, and training standard of the operation crew. Therefore, the procedure during each traffic cycle should be applied as shown in Figure (12) and according to the following steps:

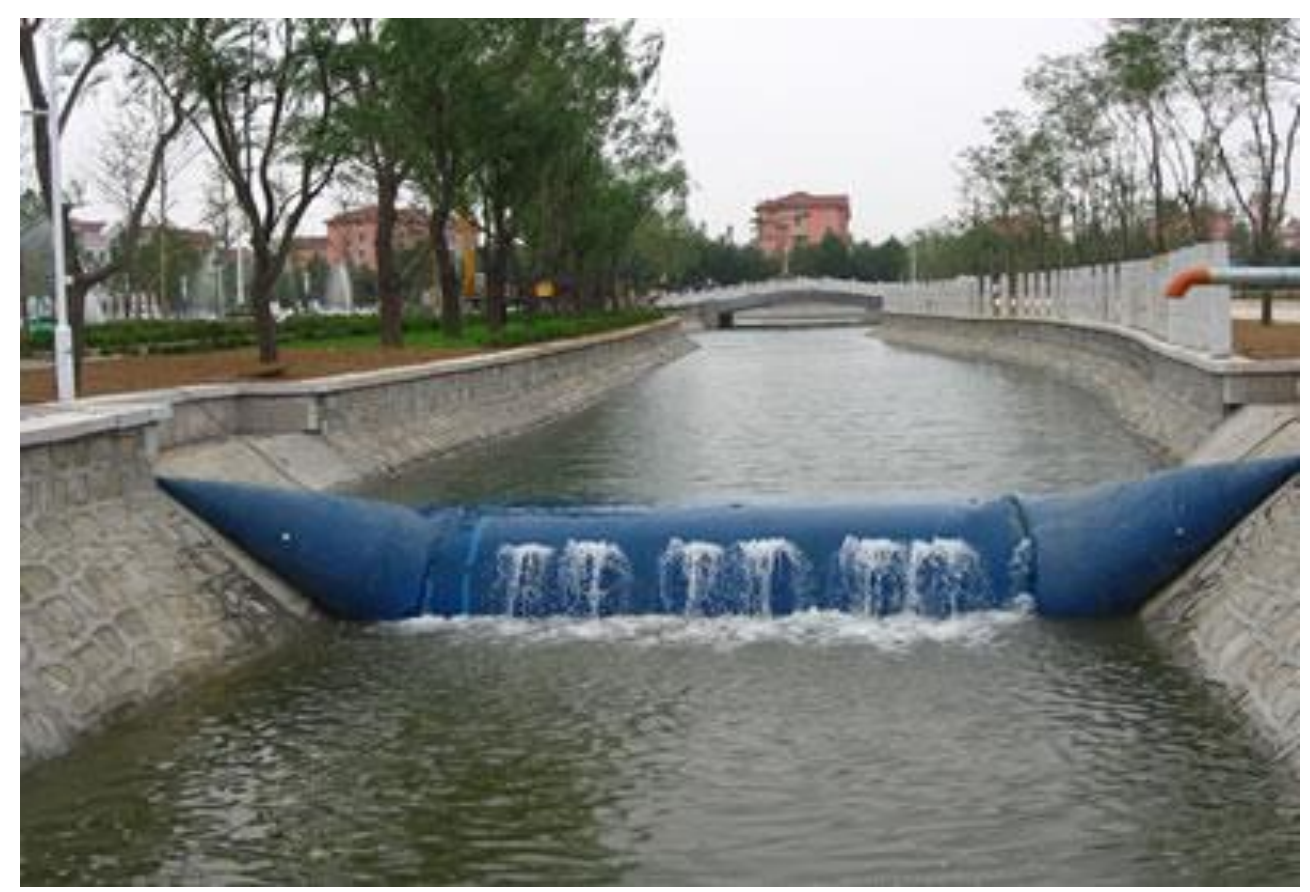

Fig. 12: Using rubber weir to raise U/S water surface level [18]

- $\quad$ While the rubber weir is completely deflated as illustrated in step (1) of Figure (12), the ships to be passed up or down through Zefta lock chamber should be docked at designated places just U/S and D/S Zefta barrages,.

- $\quad$ For safety reasons, the docking site should be $50 \mathrm{~m}$ away from U/S the rubber weir.

- $\quad$ As all ships bound U/S are docked at the designated place, the rubber weir is to be inflated to the degree that allows the discharge released $\mathrm{D} / \mathrm{S}$ Zefta barrages to be impounded U/S the rubber weir as illustrated in step (2) of Figure (12).

- The water surface at the impoundment zone U/S the rubber weir will increase until the level required for allowing the docked ships to enter the outlet diversion channel is attained. This can be considered as the steady state condition. The passing flow discharge D/S the barrages and over the rubber weir at this case will be the same. 
- $\quad$ The ships bound up and down will be simultaneously sailing through the navigation lock chamber that has a bed level of (1.50) $\mathrm{m}$. The ships bound up will sail towards Delta barrages, while the ships bound down will be docked at the waiting zone U/S the rubber weir as illustrated in step (3) of Figure (12).

- The rubber weir should be gradually deflated to get back to the starting condition which allows the docked ships to sail safely D/S to Damietta open seaport on the Mediterranean Sea as illustrated in step (4) of Figure (12).

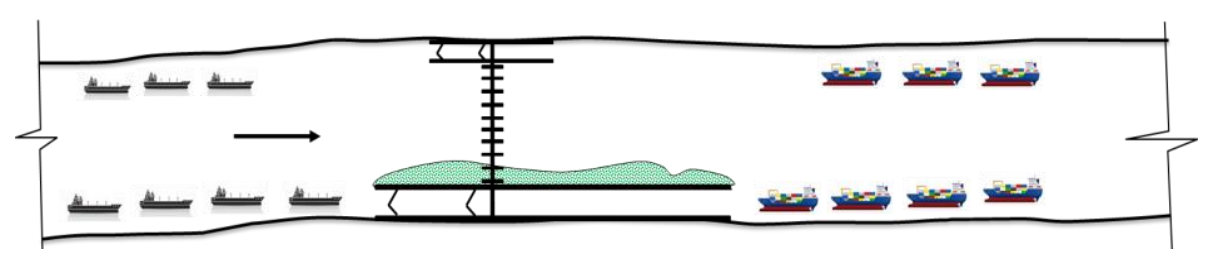

Step (1)

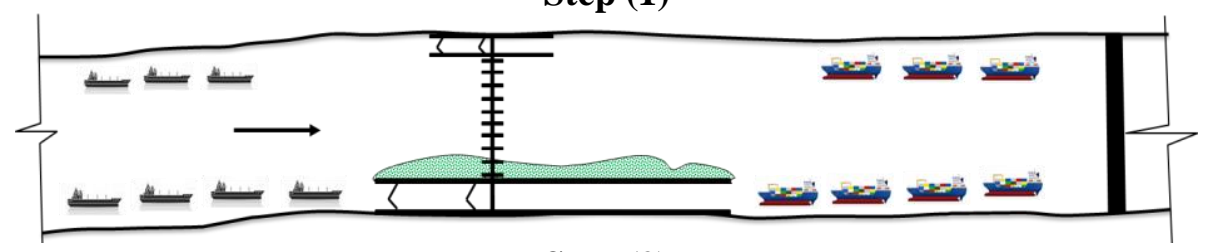

Step (2)

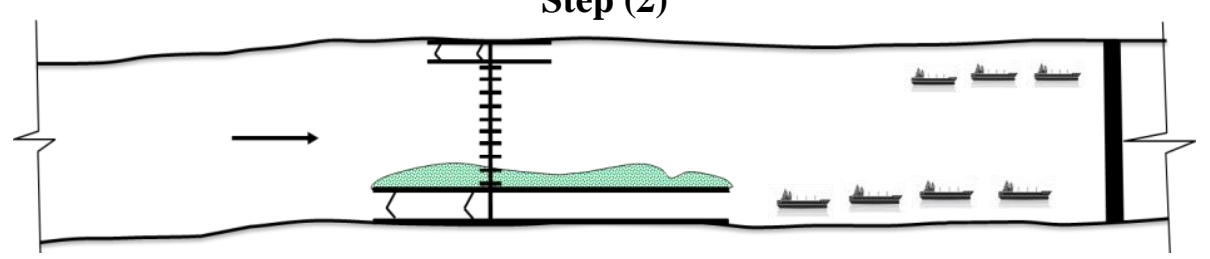

Step (3)

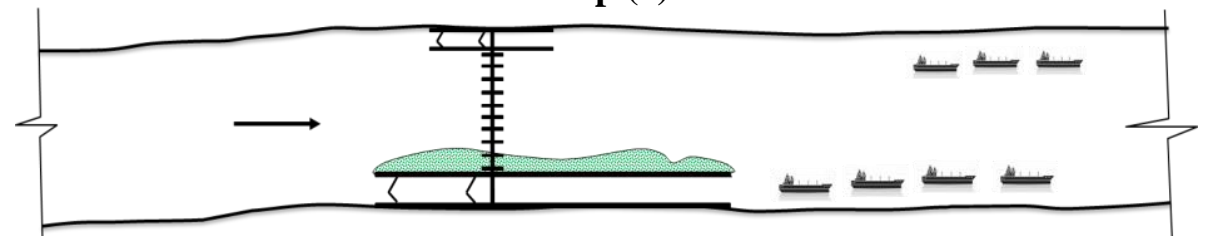

Step (4)

Fig. 13: Recommended cycle of traffic route.

To install the rubber weir in a suitable site, the most recent topographic and hydrologic conditions D/S Zefta barrages should be obtained. Detailed topographic, bathymetric, and hydrometric measurements up to the highest bank level at both sides should be conducted. The rubber weir should be installed at a right angle with the flow direction along a nearly straight reach in such a way as to provide an appropriate U/S distance to be used as a waiting zone for the ships bound up and down. To ensure sailing safely while 
passing over the deflated weir, the weir should be mounted inside a lower level trench across the channel bottom as illustrated in Figure (14). To prepare the required trench, the branch bed level should be dredged down to a minimum navigable level of $(0.50) \mathrm{m}$ for a distance of $50 \mathrm{~m} \mathrm{U} / \mathrm{S}$ and $\mathrm{D} / \mathrm{S}$ the mounting trench. To enhance the navigation condition at the two waiting zones U/S both Zefta barrages and the rubber weir as temporary terminals, the following measures should be taken:

- $\quad$ Ensure a $2.30 \mathrm{~m}$ flow depth U/S the rubber weir when releasing the minimum flow discharges D/S Zefta barrages while the weir is deflated.

- $\quad$ Navigation buoys and other aids should be positioned on both sides of the waiting zone to ensure safe docking and maneuverability while sailing.

- $\quad$ Fix bollards on both sides of the branch to hook the waiting ships during docking; and

- $\quad$ Fix staff gauges on both sides of the waiting zones to monitor the water surface level variations during inflating and deflating procedures.

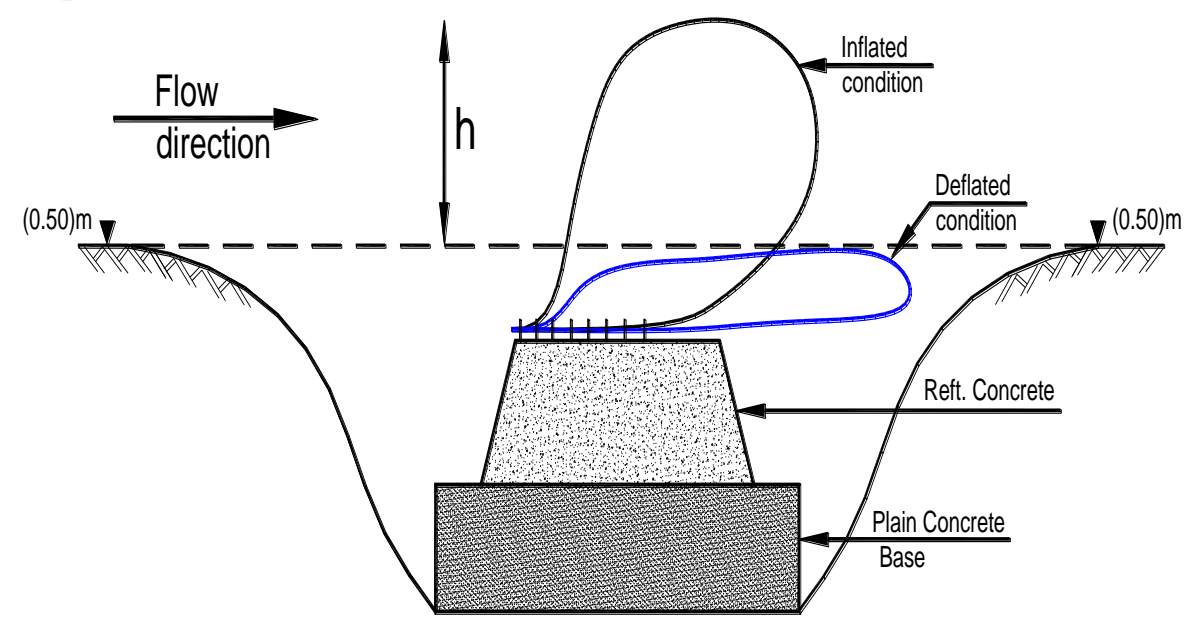

Fig. 14: Proposed mounting for the rubber weir.

Now, given that:

- The actual WS through Damietta branch D/S the outlet diversion channel is (3.10) $\mathrm{m}$ at releasing the minimum flow discharge of 4.0 million m3/day ( $46.3 \mathrm{~m} 3 / \mathrm{s})$; and

- The WS required to fulfill safe navigation D/S the existing lock is (4.00) $\mathrm{m}$. 
The period required to raise the WS from (3.10) $\mathrm{m}$ to (4.00) $\mathrm{m}$ along a distance of $1000 \mathrm{~m}$ between Zefta barrages and the rubber weir location considering a branch width of $120 \mathrm{~m}$ can be computed as follows:

Level difference $=4.00-3.10=0.90 \mathrm{~m}$

Water volume to be filled $(\mathrm{V})=1000 * 120 * 0.90=108000 \mathrm{~m}^{3}$

Time period of filling $=\mathrm{V} / \mathrm{Q}=108000 / 46.30=2332.613$ seconds $=38.87$ minutes.

\subsubsection{Proposal (2): Using an Unconventional Lock}

As the $\mathrm{D} / \mathrm{S}$ diversion channel is about $1000 \mathrm{~m}$ long and made of a trapezoidal cross section with two side slopes of 2 vertical to 3 horizontal each and (1.50) $\mathrm{m}$ average bed level as shown in Figure (15), the second proposal would be constructing a new lock within that channel. A new unconventional lock chamber could be constructed without two wing walls through the U/S part of the diversion channel as shown in Figure (16). To ensure safe navigation depth during low discharge period (winter season), the existing bed level along the whole length of the $\mathrm{D} / \mathrm{S}$ diversion channel would be dredged to a level of (0.50) $\mathrm{m}$ as shown in Figure (17).

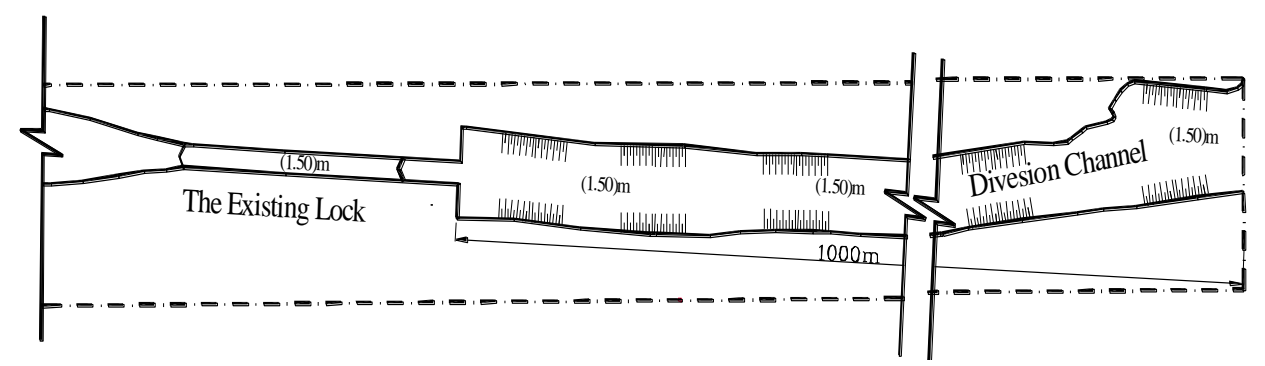

Fig. 15: Layout sketch for the existing lock chamber.

In this case, the U/S gate of the existing lock can be removed then used as the $\mathrm{D} / \mathrm{S}$ gate for the proposed unconventional lock chamber. Obviously, applying such a solution may require more water volume for filling the lock and consequently longer time periods to drain the water than the existing condition. Moreover, a special consideration would be given to the design and construction of the D/S gate. On the other hand, as the bed level of the existing lock chamber is (1.50) $\mathrm{m}$ which would be higher than that for the proposed lock, a transition zone would be constructed between the bed levels of the two lock chambers. This zone should be gradually ramped down from level (1.50) $\mathrm{m}$ to $(0.50) \mathrm{m}$. 


\subsubsection{Proposal (3): Using a Conventional Lock}

The third proposal would be the construction of a conventional lock chamber with two wing walls through the U/S part of the diversion channel as shown in Figure (18). The U/S gate of the existing lock can be then reused as a D/S gate for the proposed conventional lock chamber. In this case, the existing bed level along the whole length of the D/S diversion channel would be dredged to (0.50) $\mathrm{m}$ as shown in Figure (16). Also, the bed level should be gradually ramped down from $(1.50) \mathrm{m}$ to $(0.50) \mathrm{m}$.

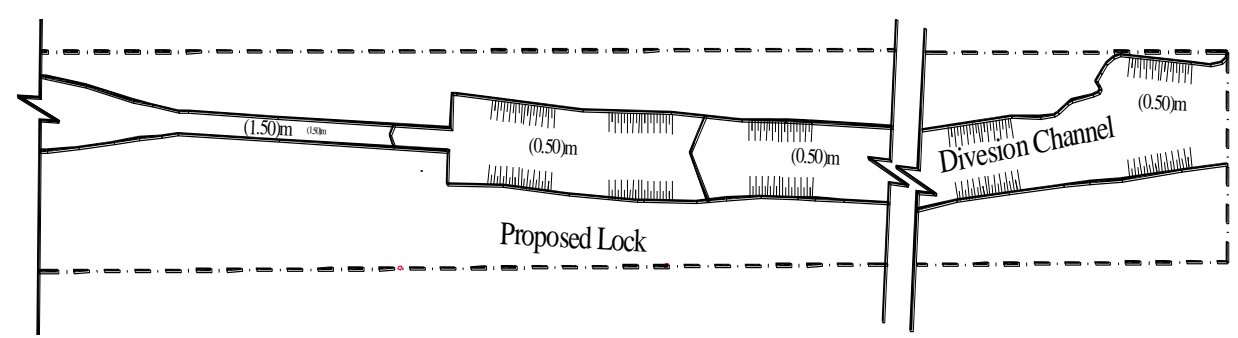

Fig. 16: Proposed unconventional lock chamber.

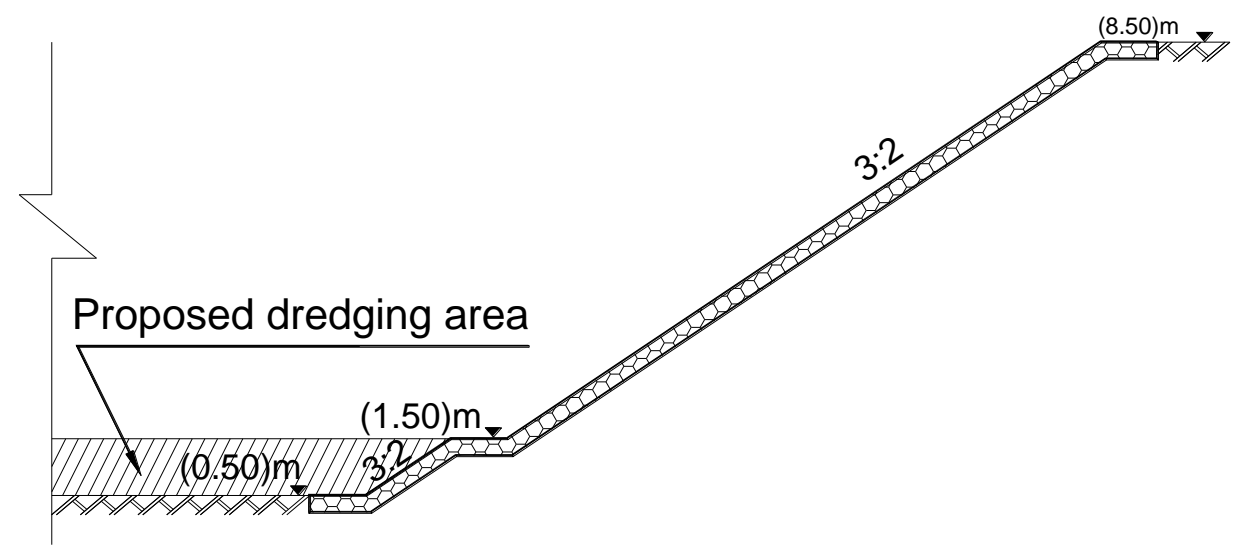

Fig. 17: Proposed dredging along the outlet diversion channel.

\section{The Differences between unconventional and conventional locks could be summarized as follow:}

- The unconventional lock has no wing walls while the conventional one has.

- The water storage capacity of the unconventional lock is bigger than that of the conventional one. Therefore, it needs longer time to be filled and drained.

- The unconventional lock has confining side fences so that boats can be prevented from sidetracking and sailing through the sloping side area; and 
- The unconventional lock is less costly.

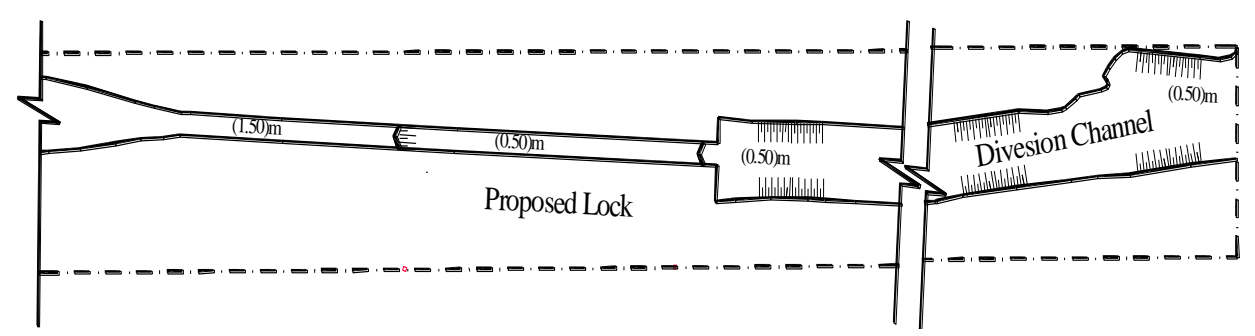

Fig. 18: Proposed conventional lock chamber.

\subsubsection{Proposal (4): Building New Barrages}

It is obvious that constructing new barrages provided with a first-class navigation lock chamber across Damietta branch D/S Zefta barrages could be the fourth proposal to solve the current problem. However, executing such proposal would be very expensive among the others and may extend the nonnavigable period to more than 4 years. Details of the proposed barrages should be designed according to recent comprehensive field measurements and an inclusive hydraulic study for a long-distance D/S the existing ones. Considering the two distributary canals of El-Mansouriya and El-Rayah ElAbbassy - established for irrigation and navigation purposes - which are located on the east and west sides of Damietta branch just U/S Zefta barrages at $\mathrm{Km} 1.225$ and 0.300 respectively, the location determination of the new barrages would be essential. This is because the selected location should ensure a sufficient WS U/S the two canals. The location and bed level of the erected navigation lock would depend on the most recently conducted field and hydraulic measurements through Damietta branch.

The new barrages would be provided with a new navigation lock of $220.0 \mathrm{~m}$ total length, $17.0 \mathrm{~m}$ width and $(0.50) \mathrm{m}$ bed level. The proposed navigation lock chamber would provide safe passage for 4 units of $100.0 \mathrm{~m}$ total length and $7.50 \mathrm{~m}$ width or 2 container units of 100.0 total length and $11.6 \mathrm{~m}$ width in both directions. The resulting water surface level through the reach between the existing and the proposed barrages - in this case - would be raised and consequently the new lock of the existing barrages would not cause any navigation problem.

\section{Considerations on Application}

The following points should be carefully and seriously considered before selecting and implementing a specific solution: 
1- The solutions given throughout the current study are based on the analysis of the hydrologic and topographic situation of the study area. As for the other aspects such as the technical, economic, social, executive and others, they should be further analyzed and taken into consideration by the respective decision-makers.

2- $\quad$ A supplementary study should be separately carried out by RTA to identify the expected density of the cargo traffic transportation through Damietta branch to decide on the best dimensions for the anticipated lock chamber and accordingly the duration and starting time of each traffic cycle in case of using an inflatable rubber weir; and

3- $\quad$ The priority to select and implement one specific solution of the four proposals should not be only based on the hydrologic and topographic aspects but also on the influence of the other ones.

\section{Conclusions}

The present study has discussed the navigation problem still suffered $\mathrm{D} / \mathrm{S}$ Zefta barrages (located across Damietta branch) especially during the low discharge release period. It explains that the WSs at that time do not meet the safe navigation requirements even after constructing a new lock at Zefta barrages and implementing a recovery project (1999-2005) for renovating the whole Damietta branch. The project was specifically intended to construct a $40 \mathrm{~m}$ wide navigable waterway for improving navigation conditions throughout the branch. Therefore, investigative hydrologic and topographic studies have been conducted to identify the reasons and introduce relevant solutions. The studies revealed two main reasons:

- Damietta branch flow capacity had increased due to the excessive dredging works that had been carried out during the recovery project. This increase caused a significant drop in WSs that were no longer able to provide the minimum water depth required for safe navigation; and

- The recorded readings taken from the staff gauge located D/S the existing weir were misleading and incorrect. This gauge was found to be directly positioned U/S a spur dike at the west bank that causes $0.50 \mathrm{~m}$ water heading up. Unfortunately, the design, planning and implementation of the new lock and $\mathrm{D} / \mathrm{S}$ diversion channel were all conducted based on such deceptive readings of the staff gauge.

Accordingly, the current study proposes four solutions based on the concept of raising the WSs (by $0.70 \mathrm{~m}$ ) or lowering the bed level of the diversion channel (by $1.0 \mathrm{~m}$ ) that is located $\mathrm{D} / \mathrm{S}$ Zefta barrages new lock. The proposals are to use a rubber weir $\mathrm{D} / \mathrm{S}$ the barrages or to construct a conventional or 
non-conventional lock within the diversion channel D/S the new lock or to construct new barrages with a new lock. The following points could also be concluded:

1. High quality hydraulic and hydrological investigations should be made prior to planning and designing any first-class navigation structure to ensure high efficiency.

2. Employing a rubber weir would be the most suitable solution for the current problem over the near and far future due to its high efficiency and few negative side effects compared with the other proposed solutions.

3. The density of river transportation traffic between Damietta open seaport on the Mediterranean Sea, Cairo and Upper Egypt depends mainly on solving the navigation problem D/S Zefta barrages.

4. Solving the navigation problem D/S Zefta barrages is urgent and should be prioritized over the existing bottlenecks through Damietta branch.

5. A detailed hydraulic study should be initiated and accomplished to check the most relevant site for any new gauge station to be installed. Also, the existing gauges should be checked along the whole River Nile to make sure the readings recorded are correct.

6. A comprehensive investigation of the past and present river morphology situation D/S Zefta barrages is essential prior to the execution of any of the proposed solutions; and

7. Raising the water surface level U/S the rubber weir for several times may cause the suspended sediment to be deposited U/S the weir. This may cause the current bed level to aggrade and get back to the condition prior to dredging and may eventually solve the problem.

\section{Recommendations}

1. A task force committee should be established to design, justify, judge, and decide the best appropriate solution for solving the navigation problem D/S Zefta barrages. Such a committee should involve high qualified and specialist members from various stakeholders.

2. Duration and starting time for each traffic cycle - in case of choosing the rubber weir as a solution - and the appropriate dimensions for the navigation lock - in case of the last three proposals - should be decided in accordance with the expected navigation development and density of traffic transportation through Damietta branch;

3. A significant effort should be directed to check the condition at the existing gauge station D/S Zefta barrage weir. This could be achieved by removing the present spur dikes $\mathrm{D} / \mathrm{S}$ the gauge station or move it to the east side just $\mathrm{D} / \mathrm{S}$ the weir or construct another gauge station near 
the outlet of the diversion channel.

4. To dispel any doubts about improper WS records, more gauge stations should be constructed along Damietta branch.

5. Navigation buoys and aids should be provided at different critical locations along the branch.

6. Dredging works should be reduced or completely stopped D/S Zefta barrages to minimize any further drop in water surface levels; and

7. Numerical or physical models can be used to predict the future effects of the solutions proposed along the study branch.

\section{Acknowledgements}

The authors would like to gratefully thank Dr.I Ahmed Fahmy Ahmed, an Emeritus Professor at Hydraulic Research Institute (HRI), National Water Research Center, Ministry of Water Resources and Irrigation, Egypt, for his valuable support and sincere advice during the scientific discussions. He has spared no effort in exerting all needed help. Indeed, he was a good advisor. The authors also wish to thank NRI administration for providing all the necessary data to complete this work.

\section{References}

[1] NRI, (1975-2020), "River Nile Study Reports", Library, El-Qanater, Cairo, Egypt.

[2] Google Earth Imagery April 2020.

[3] Sadek, N., Abd El-Fadil, M., El-Barbary, Z., and Fahmy, A., (2008), "Morphological Change Impacts on Damietta Branch Capacity". Water Research Center Journal, June 2008, Cairo, Egypt.

[4] Sadek, N., and Hekal, N., (2008), "Prediction of the Future Situation of the River Nile Navigational Path". The $12^{\text {th }}$ International Water Technology Conference Proceedings. Alexandria, Egypt. pp. 323-336.

[5] Negm, A.M., (2011), "Impact of Future Discharges on Damietta Branch Morphology", Conference: IWTC15, Alex. Egypt. DOI: 10.13140/2.1.1248.5449

[6] Nile Research Institute "NRI" Report, (2005), "Studying the Operational Rules of Damietta Branch Navigational Waterway". Report \# 28, Sept. 2005, National Water Research Center, El Qanater, Cairo, Egypt.

[7] NRI, (2005), "Establishing Operational rules to solve navigation problems in Dammietta branch", Arabic Report, Aug. 2005.

[8] Raslan, Y., Sadek, N., and Attia, K., (2009), "Impact of Navigation Development on Damietta Branch", Water Research Center Journal, Issue 46, pp. 87-101, Cairo, Egypt, 2009.

[9] Ezzat, A.S., (2010), "Hydraulic Hazards for Operating Navigation Channel in Damietta Branch", M.Sc. Thesis, Benha University, Shoubra Faculty of 
Engineering, Irrigation and Hydraulics Department, (2010).

[10] Attia, K., El-Belassy, A., El-Saeed, G. and Ezzat, A.S., (2010), "Simulation of River Regulation Works to Improve Navigation Conditions in Damietta Branch", Nile Water Science and Engineering Journal, The Nile Basin Capacity Building, (2010).

[11] Kamel, H. H., (2014), "Improving Inland Navigation of Damietta Branch", M.Sc. Thesis, Faculty of Engineering, Shebin El-Kom University, (2014).

[12] Sadek, N., Salama, R. and Kamal, N., (2015), "Effect of Bank Erosion and Bend Types on the Efficiency of Damietta Branch Navigation Path", International Water Technology Journal, IWTJ, Vol. 5 - No. 2, June 2015.

[13] BIC Rubber Dam, Beijing IWHR Corporation, (2020), http://www.environmental-expert.com/products/keyword-rubber-dam-97400.

[14] Zaoqiangdacheng Rubber Co., Ltd. (2020), Http://Www.Rubberdam.Org.

[15] Abdel-Fadil, A.M., (2017), "Comparative Study for Nasser Lake Khores Closure by Different Types of Dams", M.Sc. Thesis, Helwan University, Faculty of Engineering, Irrigation and Hydraulics Department, (2017).

[16] Arun Kumar, and Shahid ul Islam, (2019), "Hydraulic Rubber Dam", Science Direct, a Book, Chapter 6, "Inflation and Deflation of Rubber Dam", (2019)

[17] Chinese Alibaba Company for Manufacturing Rubber dams and weirs, (2020), https://www.alibaba.com/product-detail/Water-inflatable-rubberweir_1031974296.html? spm=a2700.details. maylikeexp.7.3641784apnohys.

$$
\text { DACHENG RUBBER CO., }
$$

Https://www.inflatabledam.com/project/index.html

LTD,

(2020), 


\section{حلول مقترحة لمشكلة الملاحة خلف قناطر زفتا}

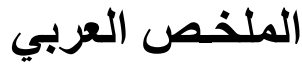

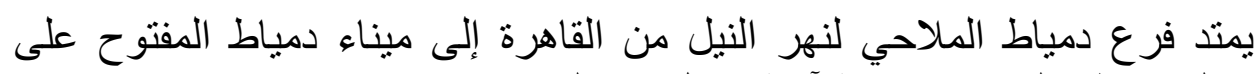

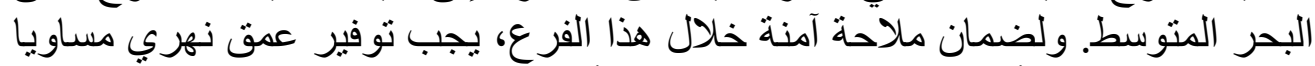

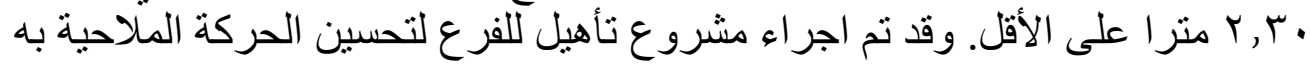

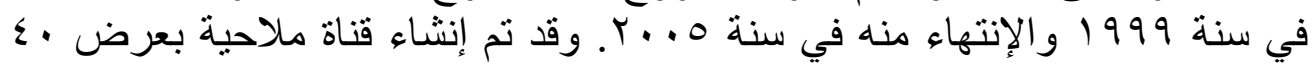

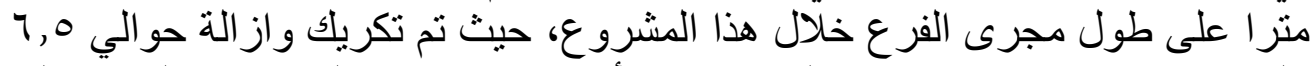

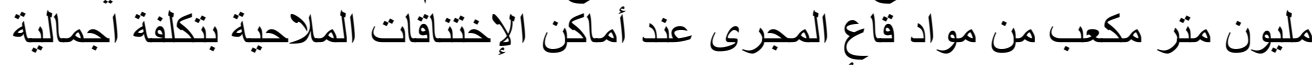

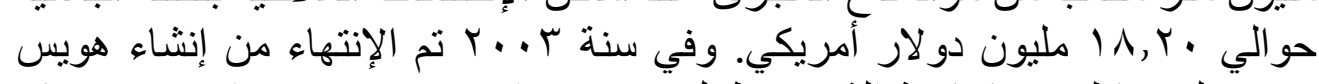

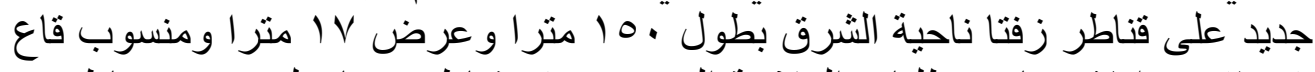

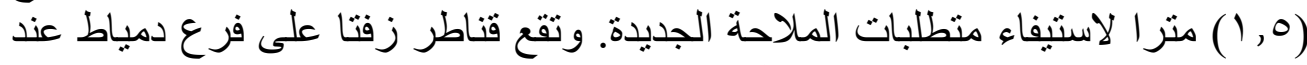

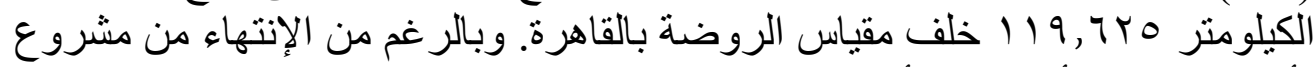

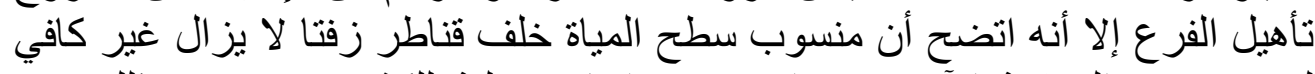

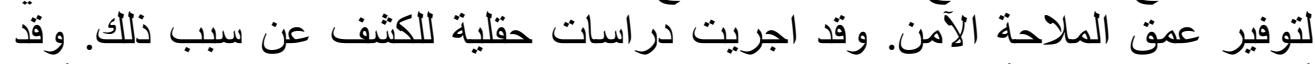

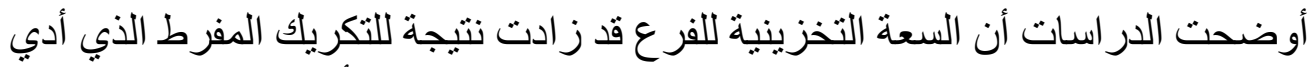

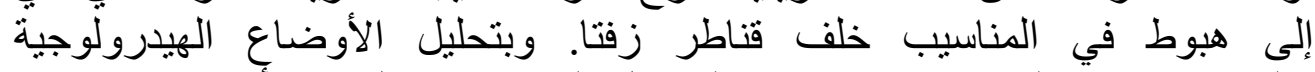

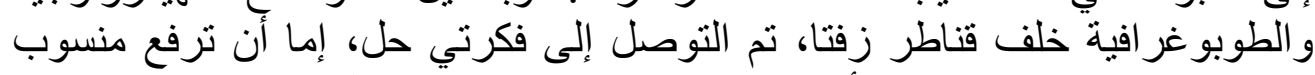

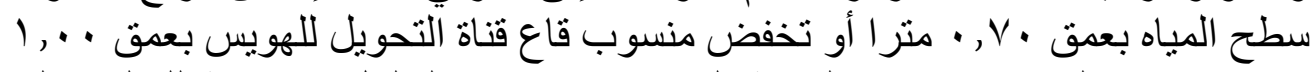

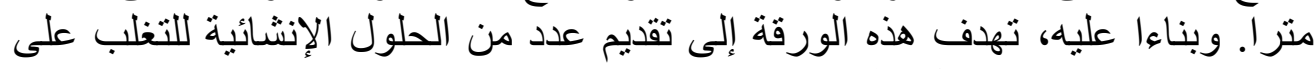

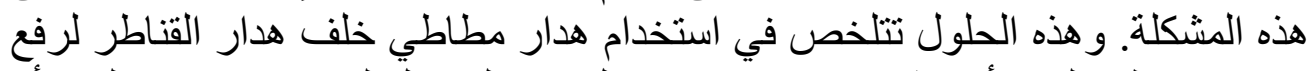

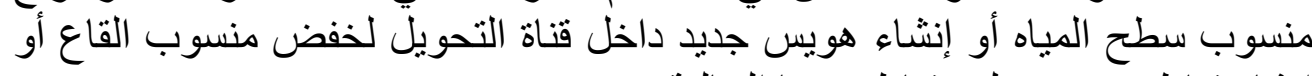
إنشاء قناطر جديدة خلف قناطر زفتا الحالية بهويس جديد. 